\title{
Research on the Collaborative Governance Model in the Charity Organization under Polycentric Perspective
}

\author{
Shilong Wang \\ School of Economics and Management, Southwest Jiaotong University, Chengdu, China \\ Email: 275641603@qq.com
}

Received 5 July 2014; revised 22 August 2014; accepted 5 September 2014

Copyright (C) 2014 by author and Scientific Research Publishing Inc.

This work is licensed under the Creative Commons Attribution International License (CC BY). http://creativecommons.org/licenses/by/4.0/

(c) (i) Open Access

\begin{abstract}
The inherent defects of the government and market make the governance of social public affairs calling for the participation of the third sector, especially in the field of charity affairs. The research of collaborative governance among charity organization, government department and economic entities plays an important role to promote the development of charity affairs. With the application of polycentric theoretical framework, the paper analyzed the structural and functional location of charity organization participating in the social governance, and preliminarily drew the outline of polycentric governance framework. Moreover, through the analysis of existing collaborative model, the polycentric governance framework was added in SFIC collaborative model, thus forming the polycentric collaborative governance model, and the explanation on the topic that some charity organizations participated in the social governance was proposed.
\end{abstract}

\section{Keywords}

Polycentricity, Collaborative Governance, Charity Organization, Governance Model

\section{Introduction}

As a new theory appeared in public management research field, the polycentric governance has been the product of "governance revolution" since the 1970s and the1980s [1]. Based on the self-governance, it is a theoretical form featured with the coexistence of multiple power centers or service centers. Starting from the theoretical perspective of public goods externality and game in public economics, it discusses how to absorb the social force to participate in the public management through effective institutional arrangement and to avoid the common evils of "tragedy of the commons" and "government failure" under the traditional bureaucratic governance 
system. The theory is intended to realize the diversification of public service suppliers, which is the collaborative cooperation among three suppliers of government, market and third sector, establish the public service supply mechanism in various forms led by the government administrative mechanism, jointly participated by the market competitive mechanism and third sector autonomous mechanism to improve the service efficiency and quality. Charity organization is an important part of the third sector and an important force within the polycentric governance framework. It is gradually entering into the decision-making system to influence the policy-making and implementation process via various strategies and evidences. Along with the gradual improvement of market economy system and gradual change of the political and legal environment, the interaction between state and society enhances the charity organization's willingness to participate in the activity, and the charity organization is developing towards the model, participating in the social governance. Charity organization shall follow the social development trend, try to break the shackle of old regime, play a role jointly with the government, enterprise and other entities, and integrate in the multi-agent collaborative network of social governance. To explore the collaborative mechanism social charity organization participating into polycentric governance, this research aims to probe into structure and function of polycentric governance, construct a polycentric collaborative governance model, and then offer theoretical illustrative guidance for directing the public affairs engagement of social charity organizations.

\section{Theoretical Basis and Literature Review}

\subsection{Charity Organization Governance}

The market has invalid space in the allocation of social resource; government also has the inefficient management, while the social organization governance can make up for the shortcomings of state and market in the regulation and coordination process. James N Rosenau, one of main founders of governance theory, held that governance was the institutional arrangement among the regulatory gaps, what's more important was the principle, norm, rule and decision-making process when two or more regulations were overlapped or in conflict, or the mutual competitive interests needed the mediation [2]. Charity organization participates in the social governance of public affairs, acts as the "buffer, transition device and regulator" between government and market, absorbs the suggestions and requirements from the relevant people in the governance process of public affairs, inputs those suggestions and requirements to the government, and provides various social means to meet the social members' diverse and multi-level wishes and realize own interest. It can not only strengthen the social tolerance, alleviate the social conflict, optimize the resource allocation and enhance the social welfare.

\subsection{Polycentric Administration}

Through years' empirical researches on the self-organizing mechanism of local public affair (such as police service, pool resource management) governance and public economic production and consumption property, Ostrom proposed the polycentric administration with the view of institutional rational selection theory [3]. In the theory, the privatization was not the only effective solution for public affair governance, and a new path shall be searched except the government and market. The polycentric self-governance structure formed through community organization spontaneous order, new "multi-level government arrangement"(featured with decentralization and overlapping jurisdiction) based on multi centers, polycentric public forum, diversified institution and public policy arrangement could realize the restraint of opportunism in the collective action and sustainable development of public interest to the maximum extent. In short, the same feature of polycentrism and governance theory was autonomy and decentralization; the former can highlight the mutual assistance and cooperation, and the latter obviously stressed the competition; when blending and becoming a way of thinking and theoretical framework, the polycentric administration became a new public management form between competition and cooperation including various centers and entities, and led the production of public goods and the governance of public affairs.

\subsection{Collaborative Governance}

In 2004, Professor Dohahua, a scholar in Harvard University firstly proposed "public-private collaborative way", and defined the collaborative governance as the joint effort from the producers except the government and sharing the discretionary power to pursue the public objective selected by the authority [4]. The most core concept in 
the collaborative governance was the collaboration and cooperation, which may exist among governments, enterprises, non-governmental organizations, or between the government and other two sectors. Concerning the necessity of collaborative governance, an early scholar Julian Le Grand analyzed the problems existed in the provided social services of education, health and housing participated by the private sector in UK Post Thatcher Era with the concept of "quasi-markets" [5]. Martha Minow researched the profit organization and non-profit organization's intervention on the education, health, welfare, legal service and other public services, and pointed out various conflicts appeared in the whole system, including those between the public sector and private sector, religion and secular, profit organization and non-profit organization, etc. As a new governance way, the collaborative governance can strengthen the interaction between citizens and government, improve public participation, coordinate the interest distribution, and promote the alleviation and solution of social contradictions [6].

\subsection{Collaborative Models}

Based on the research of existing literatures, Bryson, Crosby and Stone from the University of Minnesota proposed the analysis model of cross-sector collaboration, including initial conditions, process, structure and governance, contingencies and constraints, outcomes and accountabilities [7]. It explained the whole process of collaborative governance from the cause to the consequence and blame, while it only had some general descriptions on the explanation of collaborative process, and lacked of the comprehensive and dynamic internal explanation. Six-dimensional cooperative model proposed by CEFRIO and The Center for Technology in Government pointed out the six factors of national policy, society, economy and cultural environment, expected objective, project and collaborative performance influencing the success of the collaboration [8], while it ignored possible disputes and conflicts in the collaborative process. With the application of public-private collaborative operation model constructed by Delphi Method, Dr. Wang Qianwen from National Chengchi University divided the public-private collaboration into strategy planning, development, implementation and evaluation [9]. Related successful implementation elements were included in the appropriate stages. However, the public-private collaborative operation model is a kind of linear-structure arrangement, and there is a huge discrepancy with the complex reality, and it is hard to make a comprehensive understanding on the interaction between the public sector and private sector in the collaboration. Professor Ansell and Gash from Berkeley, University of California proposed a collaborative model consisting of starting conditions (S), facilitative leadership (F), institutional design (I) and collaborative process (C), i.e. SFIC model [10]. Each part was consisted of various segmentation variables. Wherein, collaborative process was the core of whole model, and other parts set the background or influenced. In contrast, SFIC model overcomes some common defects in the first three models, and highlights the internal complex action.

\section{Structure and Function Analysis of Polycentricity}

As a main form of "third distribution", public charity career plays an irreplaceable function and role to improve the poverty and survival situation of disadvantaged group, narrow the wealth gap, ease the social conflict and promote the social harmony.

The participating party of public charity affair covers the whole society, and it is mainly consisted of "government department, market economy entity, and social charity organization" (Figure 1). Wherein, the government department develops relevant reference policy, and leads the market economy entity to participate in the public charity; Meanwhile, it also refers to the policy suggestions from the third party social charity organization when making the relevant public charity decision; Concerning the development of public charity affair, the government also leads and supervises to ensure the public nature direction. When receiving the government's relevant preference policy, such as tax incentive, the market economy entity also actively participates in the public charity affair, broadcasts the enterprise brand to the citizen and society, and expands the force of public charity activity. The social charity organization and citizen are main carriers of public charity affair, and they drive multiple social forces to jointly participate. Specifically, on one hand, they provide the professional and targeted policy suggestion and reference for the government department to make the relevant public policy, on the other hand, they attract and drive the market economy entity to participate in the charity activity, and broadcast the image of market economy entity. The relationship among "government department, market economy entity and social charity organization" is as follows. 


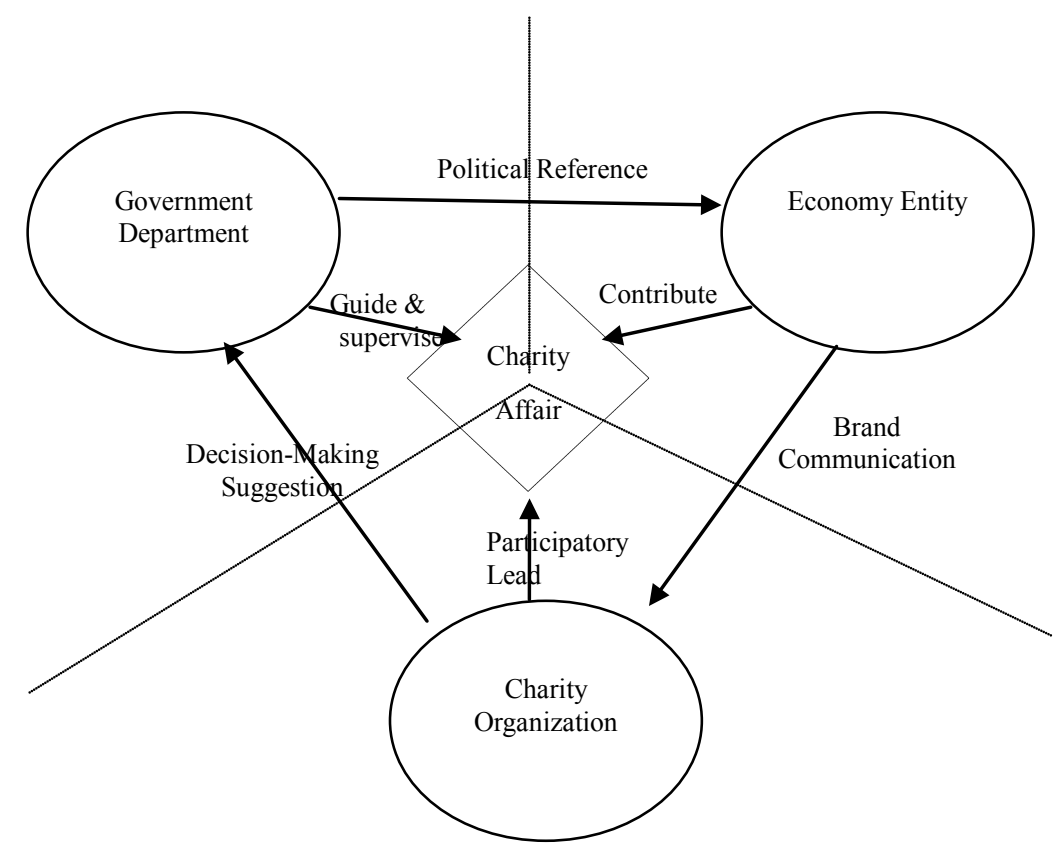

Figure 1. Structure and function diagram of polycentricity.

\section{Construction of Polycentric Collaborative Governance Model}

\subsection{Basic Model Selection and Expansion}

The governance of public charity affair involves multiple social entities, including government department, market economy entity, social charity organization, etc. It forms multiple governance centers, and it needs the collaborative cooperation of multiple centers, then it can form the effective governance. SFIC model from Ansell and Gash highlights the complex and interactive process of the collaborative cooperation. Thus it is suitable to be applied as the basic model of collaborative governance. Moreover, concerning the collaborative governance of charity organization, the charity organization shall have the collaborative cooperation with multiple entities in the external environment, thus the polycentricity-structure boundary expansion on SFIC model will be made, for the purpose of realizing the effective governance under the systematic environment.

\subsection{Construction of Polycentric Collaborative Governance Model}

In the framework that the polycentric collaboration governs public charity affair, the government department, economy entity and social charity organization jointly govern. Meanwhile, three entities play different functions in the collaborative process, and jointly form a systematic collaborative environment. The government department refers to the policy suggestions from third party social charity organization, develops relevant reference policy, leads market economy entity to participate in the public charity, and makes the top institutional design. Social charity organization is mainly responsible for the public charity affair, directly drives the multiple social entities to jointly participate, leads the smooth and effective collaborative process, and calls for the public entity's leading authorization on the affair organized by charity. Market economy entity participates in public charity affair, and it is the starting condition for the collaborative governance of public charity affair, and the reason is the limitation from government department and third-party social organization to govern the public affairs; Meanwhile, market economy entity participates in the contributed resource status of charity affair, the participation motivation includes receiving government's relevant preference policy, broadcasting enterprise brand and previous collaborative cooperation dispute with charity organization, etc. They affect the participation of market entity; therefore, they are starting condition factors of collaborative governance.

After the structure function that government department, market economy entity and third party charity organization participate in the polycentric collaborative governance is rationalized, the internal collaborative process of different entities can be divided into five parts with the reference of SFIC model, and it forms internal 
circulating ring, the five parts are process input, consensus, stage achievement, face-to-face communication, trust building. The so-called process input is to have an interdependent and common understanding and a common control of collaborative process; the so-called consensus is to reach the clear objective and have a consistent definition on the existed problem; the so-called stage achievement is to start the implementation plan of collaborative process and witness the effect of collaborative governance; the so-called face-to-face is to have a sincere communication on the process investigation among different entities; the so-called trust building is to reach the basic cooperation trust on collaborative governance process among different entities, and it can facilitate the investment and development of the next circulating process. Overall, the five steps have no sequence, they are indispensable and jointly promoting the realization of collaborative governance process among polycentric entities.

On the basis, the charity organization collaborative governance model under polycentric perspective can be summarized as follows: 1) government department is responsible for institutional design, charity organization conducts the facilitative leadership, and the economy entity starts the starting condition; 2) under the facilitative leadership of charity organization, multiple entities develop the collaborative circulation of "process input, consensus, stage achievement, face-to-face communication, trust building"; 3) through the circulating collaboration, multiple entities can realize and improve the governance effect of charity affair. Polycentric collaborative governance model of public charity affair is as shown in Figure 2.

\subsection{Model Interpretation and Evaluation}

Polycentric collaborative governance model is an expansion of SFIC model based on the internal complex interaction under the systematic environment. It stresses the collaborative cooperation among multiple governance entities; therefore, the model can extend to the following propositions for the explanation of polycentric collaborative governance model.

Proposition 1: The effect of charity affair governance is influenced by the interaction among charity organization, government department and market economy entity, and the collaborative effect depends on the level of participation.

Proposition 2: Charity organization plays the facilitative leadership on the internal effect of collaborative process, government department's institutional design restricts the effective development of collaborative governance process, and the market economy entity's contribution and participation are the starting conditions to initiate the collaborative governance.

Proposition 3: The government's tax policy and the transparency of governance process influence the market economy entity's motivation to participate in the charity governance.

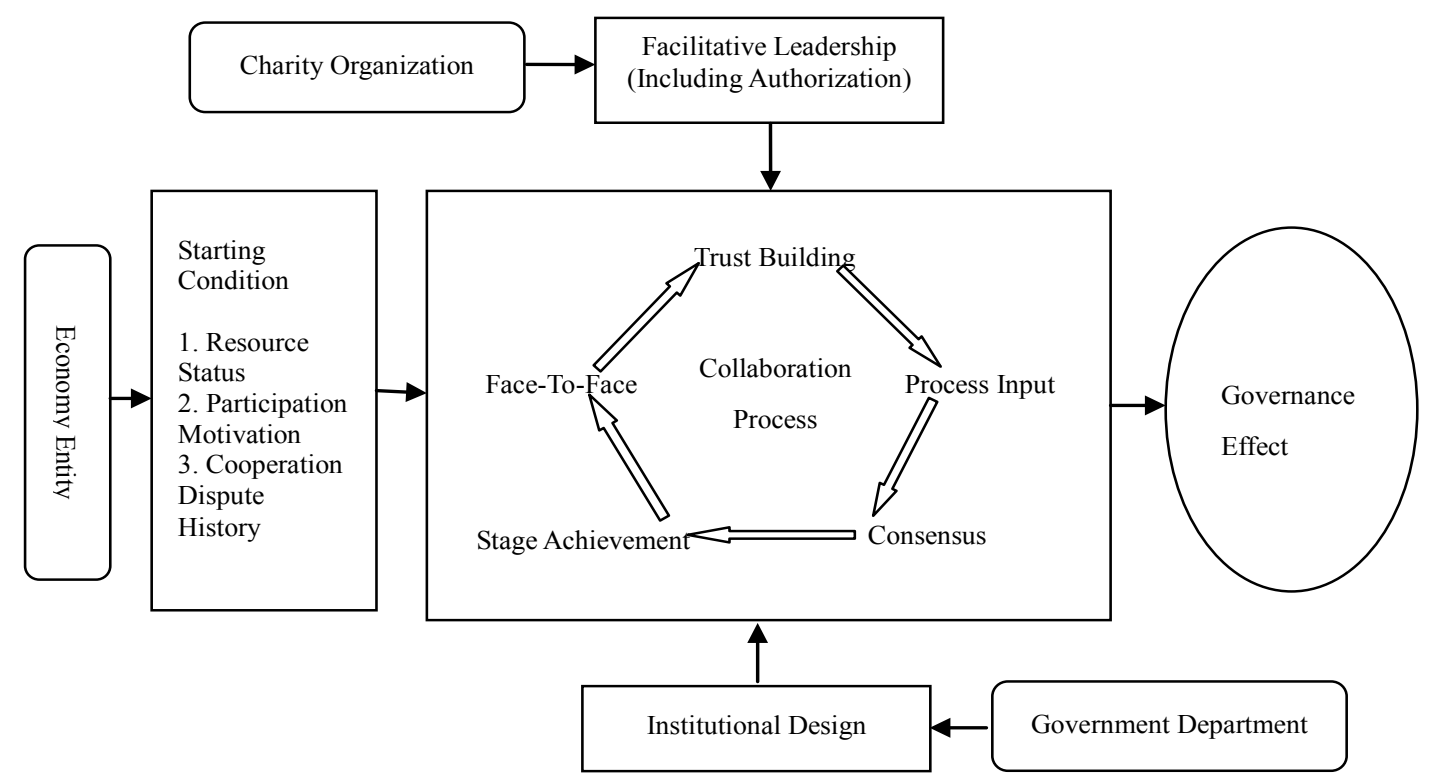

Figure 2. Polycentric collaborative governance model. 
Proposition 4: Market economy entity's participation in the charity is influenced by the previous charity cooperation dispute history and charity affair's broadcasting effect on the enterprise brand.

Proposition 5: Multi-agent collaboration process is a cyclic process which can be divided into five parts: process input, consensus, stage achievement, and face-to-face communication, trust building. They are influenced interactively, and jointly influence the effect of collaborative governance.

Proposition 6: Different entities' common understanding on interdependence, equal status in the governance process and joint control of collaborative process influence the charity investment among entities.

Proposition 7: Different entities' clear understanding on the objective of charity affair and consistent definition on the problems existed in the collaborative governance restrict the entities' understanding on the collaborative governance.

Proposition 8: Sincere communication barriers appeared in the collaborative process among different entities depend on the mutual trust and influence the development of collaborative cooperation activity at the next round.

Proposition 9: Institutional design shall ensure the equal status of multiple entities participating in the charity governance, the transparency of governance process and supervise the realization of governance objective.

Proposition 10: Facilitative leadership needs to understand the feature of collaborative governance starting condition, handle the conflicts between starting condition and internal collaborative process, especially the relationship between cooperation dispute history and trust building, participation motivation and consensus, and solve the collaborative conflicts.

Above propositions proposed in the polycentric collaboration model are logical conclusions deduced based on polycentrism and collaboration theory, and they have a certain theoretical value and significance to promote the charity affair governance practice. Although it is theoretical, the propositions need further verification and improvement in the governance practice, and it is one of key contents in the future governance research. Meanwhile, concerning the governance effect, how to highlight the social benefit and the measurement of social benefit in the governance effect will be one of the difficulties in the practical application of the model, and it needs further exploration and research.

\section{Conclusions}

The history of human development has always been accompanied by risks, such as earthquake, SARS, BSE, tsunamis. They always influence human society in unexpected ways. The risk issue is also transferred from the original professional management to broader social political level, involving the collaborative cooperation among different entities, and then the collaborative governance appears. In traditional management, the administrative single-centered order makes it hard to break through the public affair dilemma outside a minority of markets; the third sector's strong involvement and the public's comprehensive participation are needed. The polycentric governance model stresses the equal consultation and hearted cooperation among different governance entities, therefore, it is reborn as the times requirement.

Polycentric collaborative governance model expands the application border of the previous governance models, for it not only concerns the advantage of collaborative governance, but also takes into account the multiple social entities' hearted cooperation. In the charity affair governance, social charity organization, market economy entity and government department shall form the benign interaction through strategic cooperation and resource sharing to reduce the trading cost of the development of charity. The charity organization in polycentric collaborative governance model shall focus on the governance of public charity affair and charity development. Being a part in polycentric collaborative governance model can not only improve the collaborative integration ability for the charity organization to develop public charity activities, but also improve the charity organization's innovation and risk management capability. Various contradictions and dilemmas in the future social development can no longer only rely on the government or market to solve. Polycentric collaborative governance model with the participation of multiple entities will be one of mainstream models to solve the social public affairs.

\section{References}

[1] Fan, Y., Shen, C.P. and Liang, Q.L. (2013) Analysis on the Regional Cooperative Governance Based on Polycentrism. Manager Journal of China, 26, 1-2.

[2] Rosenau, J. and Czempiel, E.O. (1992) Governance without Government: Order and Change in World Politics. Cam- 
bridge University Press, London. http://dx.doi.org/10.1017/CBO9780511521775

[3] Ostrom, E. (2010) A Long Polycentric Journey. Annual Review of Political Science, 13, 1-23. http://dx.doi.org/10.1146/annurev.polisci.090808.123259

[4] Donahue, J. and Zeckhauser, R.J. (2008) Public-Private Collaboration. In: Goodin, R., Moran, M. and Rein, M., Eds., The Oxford Handbook of Public Policy, Oxford University Press, Oxford, 509-510.

[5] Le Grand, J. (1991) Quasi-Markets and Social Policy. The Economic Journal, 101, 1256-1267. http://dx.doi.org/10.2307/2234441

[6] Minow, M. (2002) Partners Not Rivals: Privatization and the Public Good. Beacon Press, Boston.

[7] Bryson, J.M., Crosby, B.C. and Stone, M.M. (2006) The Design and Implementation of Cross-Sector Collaborations: Propositions from the Literature. Public Administration Review, 66, 44-55. http://dx.doi.org/10.1111/j.1540-6210.2006.00665.x

[8] Dawes, S.S. and Ophelia, L (2004) New Models of Collaboration for Delivering Government Services: A Dynamic Model Drawn from Multi-National Research. Proceedings of the 2004 Annual National Conference on Digital Government Research, Seattle, 24-26 May 2004, 5-7.

[9] Wang, C.W. (2009) Utilizing the Delphi Method to Create an Ideal Model for Public-Private Partnerships. Journal of Policy Studies, 9, 83-146.

[10] Ansell, C. and Gash, A. (2007) Collaborative Governance in Theory and Practice. Journal of Public Administration Research and Theory, 18, 543-571. http://dx.doi.org/10.1093/jopart/mum032 
Scientific Research Publishing (SCIRP) is one of the largest Open Access journal publishers. It is currently publishing more than 200 open access, online, peer-reviewed journals covering a wide range of academic disciplines. SCIRP serves the worldwide academic communities and contributes to the progress and application of science with its publication.

Other selected journals from SCIRP are listed as below. Submit your manuscript to us via either submit@scirp.org or Online Submission Portal.
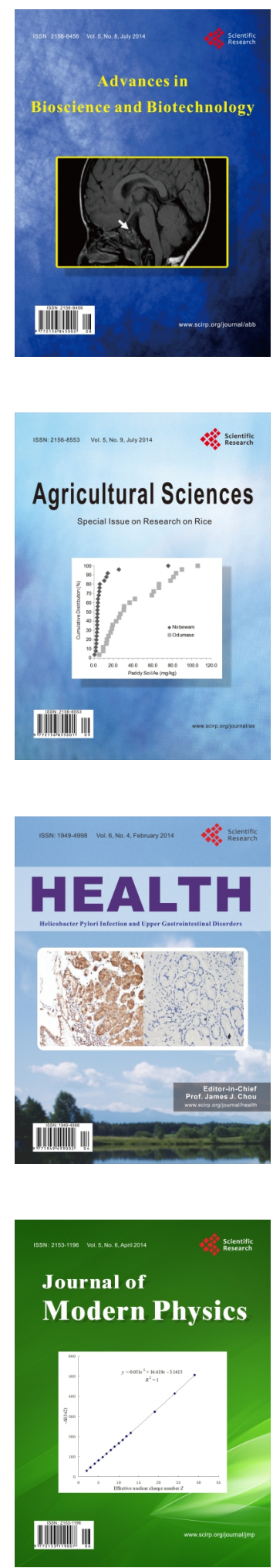
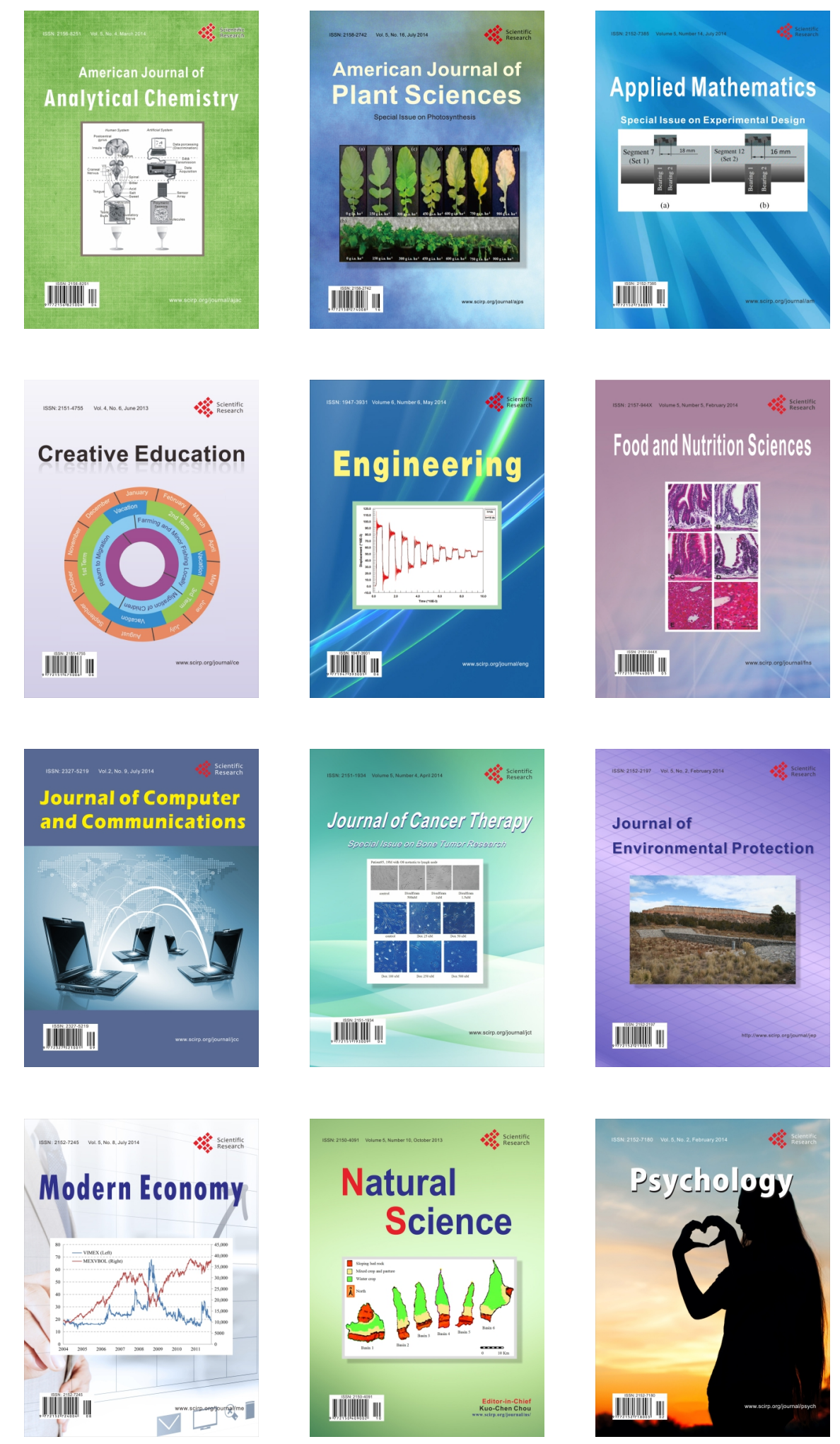